\title{
Fundamentalism and Democracy: A Dynamic Perspective
}

\author{
Luca Correani ${ }^{1, *}$ \\ ${ }^{1}$ Dept. of Economics and Business (DEIM), University of Tuscia, 01100 Viterbo, Italy \\ *Correspondence: Dept. of Economics and Business (DEIM), University of Tuscia, 01100 \\ Viterbo, Italy. E-mail: correani@unitus.it
}

Received: September 22, 2016 Accepted: October 13, 2016 Published: November 4, 2016 doi:10.5296/rae.v8i4.10060 URL: http://dx.doi.org/10.5296/rae.v8i4.10060

\begin{abstract}
We analyse the dynamics of the distribution of democratic values in a population where agents have heterogeneous preferences about democracy, distinguishing between fundamentalist-antidemocratic agents and pro-democracy agents. Cultural traits and norms are acquired through a process of intergenerational cultural transmission and socialization. The driving force in the equilibrium selection process is the education effort exerted by parents; this depends on the distribution of democratic values in the population and on expectations about future policies affecting formal and informal institutions.

The main result is that when fundamentalism is sufficiently diffused in all institutional dimensions of social life, the imposition of formal democratic rules do not significantly affect social preferences. On the other hand the model shows how a cruel fundamentalist dictatorship cannot wholly destroy democratic preferences in the population; the sole result is a fictitious homologation of manifested attitudes, with no preferences dynamics and the previous real attitudes immediately emerging as soon as dictatorship falls.
\end{abstract}

Keywords: Democracy, Cultural Change, Formation of Preferences 


\section{Introduction}

"Do individual-level attitudes play a significant role in sustaining democratic institutions at the societal level? At this point in history, democracy has a positive image almost everywhere, and the Albanians or Arabs are as likely to express a favourable opinion of democracy as are the Swedes or Swiss. But these favourable opinions are often superficial, and unless they are accompanied by deeper-rooted orientations of tolerance, trust and reciprocity, the chances are poor that effective democracy will be present at the societal level" (Inglearth and Welzel, 2004). "Public attitudes are, of course, only one part of the democratization process. The course of democratization, at least over the short term, is more likely to depend on the strategic decisions of national (or international) elites than on the responses of citizens to a public opinion survey. But in the long run, a democratic system requires a democratic public to survive and function" (Dalton and Hong, 2003).

Starting from these considerations we develop a theoretical model to see whether democracy is "exportable" into a social-institutional framework where values of tolerance and civil liberties are not sufficiently accepted by population(Note 1).

In other words, our model studies the dynamics induced by an exogenous democracy imposition, when an important proportion of antidemocratic preferences is still present or even prevalent in society; that is, can we favour the rise of democratic preferences by imposing democracy?

Precisely, we distinguish between fundamentalist-antidemocratic agents and democratic agents. Fundamentalists have a myopic vision of institutions and social life: they refuse any possible contamination of their behaviour induced by rules and customs which are not in accordance with their real attitudes. So the fundamentalist is intolerant, and in general opposed to giving civil liberties to people with different preferences. On the contrary, democratic agents have a more altruistic vision of the world: they want civil liberties for everyone, and accept diversity in all aspects of political and social life.

Cultural traits and moral codes are acquired through a process of intergenerational cultural transmission and socialization. The driving force in the equilibrium selection process is the education effort exerted by parents which depends on the distribution of democratic values in the population and on expectations about future policies regarding formal and informal institutions.

The main result is that when fundamentalism prevails in all institutional dimensions of social life, the imposition of formal democratic rules do not significantly change social preferences. This occurs because existing democrats perceive their children's "conversion" to fundamentalism as less costly than the utility cost perceived by fundamentalists when their children adopt democratic preferences: so fundamentalists' educational effort dominates the preferences dynamics. As imposition disappears the system will again converge to fundamentalist and antidemocratic institutions. This myopic behaviour in democratic agents might be strongly correlated with the level of economic development(Note 2).

On the other hand, the model shows how a cruel fundamentalist dictatorship can not destroy 
democratic preferences in the population; the only result is a fictitious homologation of manifested attitudes, a sort of behavioural inertia, with no preferences dynamics and the previous real attitudes immediately emerging when dictatorship falls.

This conclusion is paradoxical. Even more interestingly, if a fundamentalist regime allows some manifestation of democratic attitudes the quota of democratic agents within the society decreases.

This paper contributes to one strand of literature on evolution of social preferences that is the relation between agents' attitudes and the persistence of formal institutions exogenously imposed to the population. In fact we ascertain a substantial lack of theoretical dynamic models about this topic. To the best of our knowledge we can find a similar approach in Cerqueti et al. (2013) and Corneo and Jeanne (2009). In Cerqueti et al. (2013) the authors develop an evolutionary theory of social tolerance by using replicator dynamics. In Corneo and Jeanne (2009) the author proposes a theory of tolerance using the approach of symbolic values. However in both these works the effects of externally imposed institutions are nor analysed. Our is one of the very attempts at modelling these effects by using the well tested approach of preference transmission introduced by Bisin and Verdier (2000).

The reminder of the paper is organized as follows. Section 2 describes the basic model. Sections 3 and 4 discuss, respectively, the mechanisms of cultural transmission and institutional evolution. Section 5 presents a brief analysis of the steady states of the model and section 6 analyses some possible scenarios. Section 7 concludes.

\section{The Model}

The model proposes a simple overlapping generation framework to explain whether democracy is exportable into a population with heterogeneous agents having different preferences about democratic values. It defines two types of agents: fundamentalists and democrats. The agents are distinguished in relation to their own intensity of tolerance towards democratic values, $T=\left\{t_{1}, t_{2}\right\}$ with $t_{1}$ indicating a democratic type (with the highest tolerance) and with $t_{2}$ a fundamentalist (with the lowest tolerance); clearly $t_{1}>t_{2}$.

The probability of an agent being democratic is $\operatorname{prob}\left\{t_{1}\right\}=z_{t}$. Although we allow for different degrees of intensity in the acceptance of democratic values, we have assumed that only the extreme values are present in the society. Fundamentalist agents do not support democratic values and their preferences do not depend on institutional rules; they always choose to manifest their real attitude, consisting in a total opposition to democratic principles, and always isolate themselves by refusing any socialization with different types. The fundamentalist's utility function is $U_{2}=U_{2}\left(\left|m_{i}-t_{2}\right|\right)$ where $m_{i}$ is the attitude manifested, with $\partial U_{2} / \partial\left|m_{i}-t_{2}\right|<0$ : so $m_{i}^{*}=t_{2}$ is always chosen. 
On the contrary, democratic types choose to manifest an attitude that creates the minimum frictions with both their real attitude $t_{1}$ and the formal and informal rules existing in society. Democratic agents have to maximize their utility function $U_{1}=U_{1}\left(\left|m_{i} \bar{e}-\theta\right|, A\right)$, where $\bar{e}=(1,1,1)$ and $t_{2} \leq m_{i} \leq t_{1}$ the attitude declared, $\theta=\left(\theta^{f}, \theta^{n f}, t_{1}\right)$ the vector of institutions with $t_{2} \leq \theta^{f} \leq t_{1}$ formal institutions, $t_{2} \leq \theta^{n f} \leq t_{1}$ informal institutions and $t_{1}$ being the fixed real attitude of the agents.

The term $A \in \mathfrak{R}_{+}^{3}$ indicates a vector of fixed parameters assigning a degree of importance to each of the corresponding dimensions of $\theta$. These parameters measure how strongly the specific institutional dimensions matter in the society from the democratic type point of view.

In a fundamentalist dictatorship, for example, the imposed formal institutions $\theta^{f}=t_{2}$ are the most important dimensions, while informal institutions and personal values are irrelevant, that is their importance can be supposed null. As we will see later, this hypothesis produces interesting results about the effect of fundamentalism on the dynamics of a population's preferences.

The utility function decreases in the "distance" between the manifested attitude and an element of institutional vector $\theta$, that is $\partial U_{1} / \partial\left|m_{i} e_{j}-\theta_{j}\right|<0$ where $j=1,2,3$, with $e_{j}$ being the unit vector denoted $e_{1}=(1,0,0), e_{2}=(0,1,0), e_{3}=(0,0,1)$.

Given $m_{1}^{*}\left(\theta^{f}, \theta^{n f}\right)=\arg \max U\left(\left|m_{i} \bar{e}-\theta\right|, A\right)$ as the optimal manifested attitude with an institutional vector $\theta=\left(\stackrel{m}{\theta}^{f}, \theta^{n f}\right)$, where the fixed parameter is understood to be $t_{1}$. So the manifested attitudes are all possible $m_{i}$ between the minimum value $t_{2}$ and the maximum $t_{1}$ (Note 3).

Given the utility function we can define the corresponding maximum value function as

$$
V\left(\theta^{f}, \theta^{n f}, A\right)=U\left(\left|m_{1}^{*}\left(\theta^{f}, \theta^{n f}, A\right)-\theta\right| A\right)
$$

with $\partial V\left(\theta^{f}, \theta^{n f}, A\right) / \partial \theta^{f}>0$ and $\partial V\left(\theta^{f}, \theta^{n f}, A\right) / \partial \theta^{n f}>0$; that is, democratic agents obtain higher values of satisfaction if institutions are close to their real attitude. Clearly $\partial m_{1}^{*}\left(\theta^{f}, \theta^{n f}, A\right) / \partial \theta^{f}>0$ and $\partial m_{1}^{*}\left(\theta^{f}, \theta^{n f}, A\right) / \partial \theta^{n f}>0$. So $V(\theta)$ is strongly increasing in $\theta$ that is $V\left(\theta^{a}\right)>V\left(\theta^{b}\right)$ if $\theta^{a} \geq \theta^{b}$ and, for a fixed set of parameters, we can write $V\left(t_{1}, t_{1}\right) \geq V\left(t_{i}, t_{j}\right) \geq V\left(t_{2}, t_{2}\right)$ for all $i \neq j$. Moreover $V\left(t_{1}, t_{2}\right) \geq V\left(t_{2}, t_{1}\right)$ if formal institutions are more important than informal institutions with equality when they have identical relevance(Note 4). Likewise, $V\left(t_{i}, t_{j}\right)=V\left(t_{i}, t_{k}\right)$ and $V\left(t_{k}, t_{i}\right)=V\left(t_{j}, t_{i}\right)$ if, respectively, if $\theta^{n f}$ and $\theta^{f}$ have no weights; this is because the institutional dimension with no weight does not affect the agent's choices. 


\section{Dynamic of Preferences}

Now we expand the model by adding the temporal dimension and considering an overlapping generation mechanism by which parents and society transmit cultural traits to future generations. Each agent lives two periods. In the first period she is a child and she has no specific preferences; in the second she becomes an adult with a definite attitude toward democratic values and chooses to manifest the attitude maximizing her utility function. Preferences are transmitted to the child by the education effort of the parent (vertical transmission) and by the cultural influence of society (oblique transmission)(Note 5): if the child does not learn from the parent, she adopts the preferences of a randomly chosen adult. Parents want to maximize their child's future well-being, but they evaluate the welfare of their children through their own preferences structure according to the hypothesis of imperfect empathy (see Cavalli-Sforza and Feldman, 1981 and Bisin and Verdier, 2000). Empathy is the psychological process that consists in directly absorbing the emotional condition of another person; the imperfection we attribute to this process consists in a sort of myopic behaviour of a parent who evaluates the future choices of her child without considering the child's effective attitude but exclusively using one's own.

To formalize these concepts suppose at time $t$ each adult of type $t_{i}$ has a child and chooses an effort $\tau_{i}^{t}$ to educate her. This effort equates the probability the child will adopt parent's preferences, $0 \leq \tau_{i}^{t} \leq 1$. Now, letting $P_{t}^{i, j}$ be the transition probability that a child of parent $t_{i}$ is of type $t_{j}$ and considering a democratic adult, we can write

$$
\begin{aligned}
& P_{t}^{1,1}=\tau_{t}^{1}+\left(1-\tau_{t}^{1}\right) z_{t}, \\
& P_{t}^{1,2}=\left(1-\tau_{t}^{1}\right)\left(1-z_{t}\right),
\end{aligned}
$$

where $z_{t}$ is the proportion of democratic adults at time $t$. Similarly, for the fundamentalist adult we get

$$
\begin{gathered}
P_{t}^{2,2}=\tau_{t}^{2}+\left(1-\tau_{t}^{2}\right)\left(1-z_{t}\right), \\
P_{t}^{2,1}=\left(1-\tau_{t}^{2}\right) z_{t} .
\end{gathered}
$$

Given these probabilities, we can characterize the dynamic behaviour of $z_{t}$ by the following difference equation:

$$
z_{t+1}=z_{t} P_{t}^{1,1}+\left(1-z_{t}\right) P_{t}^{2,1}
$$

Which, substituting for $P_{t}^{1,1}$ and $P_{t}^{2,1}$, becomes

$$
z_{t+1}=z_{t}+z_{t}\left(1-z_{t}\right)\left(\tau_{t}^{1}-\tau_{t}^{2}\right) .
$$

Proposition 1: The difference equation (7) has two unstable fixed points, $z=0$ and $z=1$, 
and a unique stable fixed point $z=z^{*}$ with $\tau^{1}=\tau^{2}$.

(Proof: see appendix).

As we can see, the dynamics of the population's preferences depend on the parent's educational effort. A parent of type $t_{i}$ chooses the educational effort $\tau \in[0,1]$ that maximizes

$$
\Gamma=\beta\left(P_{t}^{i, i} U_{t}^{i, i}\left(\theta^{k, h}\right)+P_{t}^{i, j} U_{t}^{i, j}\left(\theta^{k, h}\right)\right)-C\left(\tau_{t}^{i}\right),
$$

where $\beta$ is the discount rate, $C\left(\tau_{t}^{i}\right)$ the cost of educational effort and $U^{i, j}\left(\theta^{k, h}\right)$ the expected utility from the economic action of a child of type $t_{j}$, as perceived by a parent of type $t_{i}$ when she expects $\theta^{h, k}=\left(t_{h}, t_{k}, t_{1}\right)$.

Assume that $C\left(\tau_{t}^{i}\right)$ is twice continuously differentiable and strictly convex with $C(0)=0$, $C^{\prime}(0)=0$ and that, for all $\tau, C^{\prime \prime}>C^{\prime}>0$ (Note 6). In order to assess $U_{t}^{i, j}$, a parent of type $t_{i}$ uses his own payoff structure (imperfect empathy), therefore, given $\theta^{h, k}$ we must have $U_{t}^{i, i}\left(\theta^{h, k}\right) \geq U_{t}^{i, j}\left(\theta^{h, k}\right)$, that is each parent prefers a child that adopts her own preferences.

Solving the maximization problem and suppressing the time indicators, we obtain the following conditions:

$$
\begin{aligned}
& \beta\left(U^{1,1}-U^{1,2}\right)(1-z)=C^{\prime}\left(\tau^{1}\right), \\
& \beta\left(U^{2,2}-U^{2,1}\right) z=C^{\prime}\left(\tau^{2}\right),
\end{aligned}
$$

by which, using the implicit function theorem, we get

$$
\begin{gathered}
\frac{\partial \tau^{1}}{\partial z}=-\frac{\beta\left(U^{1,1}-U^{1,2}\right)}{C^{\prime \prime}\left(\tau^{1}\right)} \leq 0, \\
\frac{\partial \tau^{2}}{\partial z}=\frac{\beta\left(U^{2,2}-U^{2,1}\right)}{C^{\prime \prime}\left(\tau^{2}\right)} \geq 0 .
\end{gathered}
$$

The educational effort of type $t_{1}$ decreases as the proportion of democratic agents increases.

In fact, higher values of $z$ mean a higher probability the child assumes the same preferences as the parent simply by socializing with a member of society; this induces the parent to reduce the educational effort. Similarly, if the proportion of democratic agents increases, the fundamentalist parents must intensify their educational effort.

Moreover, fundamentalists have a total aversion to socialise with types manifesting different attitudes; they do not tolerate any deviation from their moral codes, and evaluate such a deviation as highly expensive. On the contrary, conversions of different types to their preferences has a very high value for them. To simplify the analysis we can state the 
following formal definition of imperfect empathy, which will be useful to compute the value functions for each type of agent:

Definition: Imperfect empathy with total socialization aversion: for the type $t_{2}$, $U^{2,1}=U_{2}\left(\left|t_{1}-t_{2}\right|\right)$ given the belief $t_{1}=\arg \max U_{1}\left(\left|m_{i} \bar{e}-\theta\right|, A\right)$ for all $\theta$ and $m_{1}^{*} \neq m_{2}$ (expensive deviation hypothesis). On the contrary, if $m_{1}^{*}=t_{2}$ then $U^{2,1}=U_{2}\left(\left|t_{2}-t_{2}\right|\right)$ (hypothesis of highest utility from "conversion").

\section{Formal and Informal Institutions}

In this model we distinguish between formal and informal institutions, according to North's definition (see Bisin and Verdier, 2001), and formalize the concept by using the vector $\theta=\left(\theta^{f}, \theta^{n f}, m_{1}\right)$. According to this definition formal institutions are the political, social and economic regulations in force; they usually emerge to increase the effectiveness of habits, customs and religious traits (informal institutions) diffused in the population. So we can suppose that in each period informal institutions represent the level of democratic values of prevailing type. If the fraction $z_{t}$ is larger than $\frac{1}{2}$, then democratic agents are in the majority and their attitudes constitute informal institutions, and $\theta^{\text {nf }}=t_{1}$. On the other hand, when $z_{t}$ is less than $\frac{1}{2}$, the level of $\theta^{n f}$ will be strongly affected by fundamentalist customs and $\theta^{n f}=t_{2}$.

To summarize

$$
\theta^{n f}\left(z_{t}\right)=\left\{\begin{array}{lll}
t_{1} & \text { if } & z_{t}>\frac{1}{2} \\
t_{2} & \text { if } & z_{t} \leq \frac{1}{2}
\end{array}\right.
$$

The mechanism we have introduced allows us to formalise the idea that democratic habits and beliefs spread when there is not sufficient social aversion to oppose them.

On the other hand, institutions reduce the cost of individual convictions, so ideologies, religions and moral codes can produce very important institutional alterations (see Bisin and Verdier, 2001). This consideration allows us to assume that when formal institutions freely evolve (that is without exogenous imposition) they will tend to coincide with informal rules as time goes by, that is for a fixed level of $\theta^{n f}, \theta^{f} \rightarrow \theta^{n f}$ during a finite time $t$. 


\section{The Steady States}

We can now characterize the steady states according to the expected level of formal and informal institutions.

Lemma 1: Given an expected institutional vector $\left(\theta^{f}, \theta^{n f}\right)$ then $\tau^{1} \geq \tau^{2}$ when $z_{t} \leq z^{*}\left(\theta^{f}, \theta^{n f}\right)$ where

$$
z^{*}\left(\theta^{f}, \theta^{n f}\right)=\frac{U^{1,1}\left(\theta^{f}, \theta^{n f}\right)-U^{1,2}\left(\theta^{f}, \theta^{n f}\right)}{U^{1,1}\left(\theta^{f}, \theta^{n f}\right)-U^{1,2}\left(\theta^{f}, \theta^{n f}\right)+U^{2,2}-U^{2,1}} .
$$

(Proof: see appendix).

Lemma 2: Each institutional combination generates a unique and different stable steady state $z_{i, j}=z^{*}\left(t_{i}, t_{j}\right)$.

However, given the assumptions on institutions we only consider institutional situations $\left(\theta^{f}, \theta^{n f}\right)$ with $\theta^{f}=t_{1}, t_{2}$ and $\theta^{n f}=t_{1}, t_{2}$; so the following relations hold:

1) $z_{1,1} \geq z_{1,2}, \quad z_{1,1} \geq z_{2,1}$ and $z_{1,1} \geq z_{2,2}$;

2) $z_{2,2} \leq z_{2,1}$ and $z_{2,2} \leq z_{1,2}$;

3) $z_{1,2} \leq z_{2,1}$ where equality holds if different dimensions of institutional vector have the same relevance.

(Proof: see appendix)

Given that formal institutions tend to coincide with informal institutions, we can consider as a possible final state the points $z_{i, j}$ with $i=j$.

\section{Imposing Formal Institutions}

According to the above characterization of steady states and the definition of imperfect empathy, and defining $U_{a, b}^{i, j}$ as the value of expected utility $U^{i, j}$ in the equilibrium point $Z_{a, b}$, we can state the following propositions:

Proposition 2: assume $U_{2,2}^{1,1}-U_{2,2}^{1,2}<U^{2,2}-U^{2,1}, z_{2,2}$ as the initial point, and the 
exogenous imposition of democracy such that $\theta^{f}=t_{1}$ then: 1) if $z_{1,2}>\frac{1}{2}$ then $z_{t}$ will converge to $z_{1,1}$ (democracy consolidates). 2) If $z_{1,2} \leq \frac{1}{2}$ then $z_{t}$ will converge to $z_{1,2}$, but when the imposition disappears, $z_{t}$ will go back to $z_{2,2}$ (fragile democracy).

(Proof: see appendix).

Proposition 3: assume $U_{1,1}^{1,1}-U_{1,1}^{1,2}>U^{2,2}-U^{2,1}, z_{1,1}$ as the initial point and the imposition of fundamentalist dictatorship such that $\theta^{f}=t_{2}$ then: 1) if $z_{2,1}<\frac{1}{2}$ then $z_{t}$ will converge to $z_{2,2}$ (fundamentalist dictatorship consolidates). 2) If $z_{2,1}>\frac{1}{2}$ then $z_{t}$ will converge to $z_{2,1}$, but when the imposition disappears $z_{t}$ will go back to $z_{1,1}$ (fragile fundamentalist dictatorship).

(Proof: see appendix)

By proposition 2, "democracy is exportable" only if the "transitory" steady state $z_{1,2}$ is sufficiently high; this occurs when $U_{1,2}^{1,1}-U_{1,2}^{1,2}>U^{2,2}-U^{2,1}$. Such a relationship fixes the idea that the net "utility gains" of a democratic type from having a child with her own preferences must be higher than the corresponding net "utility gains" of a fundamentalist parent. Deviations from democratic values must be perceived as very expensive. So imposing formal institutions can induce a change in customs but only if the agent sustains democratic values sufficiently. As we have reported in the introduction, nowadays democracy has a positive image almost everywhere, but a deeper analysis shows as these favourable opinions are often superficial, and accompanied by deeper-rooted orientations of religious and political intolerance. Such a situation makes the "export of democracy" very vulnerable to fundamentalist contaminations; probably democracy can not sustain itself. Thus, when deviations are not expensive, the imposed democracy only produces a temporary change in formal institutions $\theta^{f}$, without systematically affecting social and cultural norms $\theta^{\text {nf }}$. In this case democracy is fragile and permitting a free evolution of institutions will destroy the imposed democracy. The rise of Nazi dictatorship is an emblematic historical example of an imposed democracy changing into a cruel fundamentalist dictatorship. In terms of our model, the disastrous economic conditions under the fragile Weimar Republic and the hierarchic and paternalistic authoritarian structure of the German family and society (informal institutions) created the conditions for a low level of the utility difference $U_{1,2}^{1,1}-U_{1,2}^{1,2}$, opening the way for a rapid increase of fundamentalist education effort and the consequent diffusion of undemocratic values (convergence toward the state $z_{2,2}$ ). The brand-new German democracy turned out to be extremely fragile; in fact democratic elections confirmed full power for the 
fundamentalist Nazi party transforming a Democracy in a cruel dictatorship (see Dalton and Ong, 2003 and North, 1990).

In accordance with Verba (1965), proposition 3 shows that a consolidated democracy might change towards undemocratic forms of governments. In fact, when $z_{2,1}<\frac{1}{2}$ and informal democratic institutions do not receive sufficient support (relevance) compared with formal institutions (that is $U_{2,1}^{1,1}-U_{2,1}^{1,2}<U^{2,2}-U^{2,1}$ ), the exogenous imposition of fundamentalist reform of formal institutions (perhaps induced by poor economic conditions) can generate a tragic political change in regime, characterized by the end of democracy and the rise of fundamentalist dictatorship.

\subsection{Other Possible Scenarios}

The model shows that democracy can fall spontaneously even where there is no exogenous imposition of fundamentalist preferences. Formalizing, let us define a $\bar{z}>\frac{1}{2}$ so that for all $\frac{1}{2}<z_{t}<\bar{z}$, if $E\left(\theta^{f}\right)=t_{2}$ with $z_{2,1}<\frac{1}{2}$, then $z_{t+1}\left(z_{t}\right)<\frac{1}{2}$ and suppose we start from $\frac{1}{2}<z_{1,1}<\bar{z}$. By proposition 2, with $E\left(\theta^{f}\right)=t_{2}$ we see that in the first period $z_{t}$ will converge to $Z_{2,1}<\frac{1}{2}$ overcoming $Z=\frac{1}{2}$; but in the second period, $Z<\frac{1}{2}$ so informal institutions change and the system spontaneously converges to $z_{2,2}$. Even with consolidated democratic institutions, if the proportion of democrats is not sufficiently large, it is sufficient that their expectations are pessimistic with regards to the immediate future of formal institutions to produce a spontaneous convergence toward fundamentalist equilibrium (self-fulfilling expectations). It is reasonable to assume that this pessimism may be generated by exogenous factors inducing political uncertainty such as terrorism, wars, globalization etc(Note 7).

On the other hand, the model allows us to study whether an imposed and cruel dictatorship, which destroys any possibility to freely manifest different preferences (an emblematic example was the recent Taliban dictatorship in Afghanistan), can produce such a significant change in social preferences that after some time all individuals are fundamentalist and the dictatorship has the full support of the population. History seems to tell us that dictatorships can not systematically affect people with different preferences; cultural groups tend to maintain their originality even if they are constrained to manifest different attitudes during the dictatorship. To formalize this idea, let us suppose the imposition of $\theta^{f}=t_{2}$ and a reduction of the relevance of both $\theta^{\text {nf }}$ (informal institutions) and $t_{1}$ (personal democratic attitude)(Note 8 ), so that the optimal choice for a democratic type is $m_{1}^{*}\left(\theta^{f}, \theta^{n f}\right) \cong t_{2}$ (Note 9). In this situation we do not observe any significant dynamics in population distribution of 
types because $U^{i, i} \cong U^{i, j}$ for each type of agent and so, by the maximization problem, $C^{\prime}\left(\tau^{i}\right)=0, i=1,2$. Dictatorial regimes can not wholly "tame" population; in the long run the former distribution of types survives fundamentalist governments remerging as dictatorship disappears.

\section{Concluding Remarks}

This paper demonstrates that the effort by which individuals transmit democratic preferences to future generations plays a fundamental role in generating transition from fundamentalist autocracy to democracy, particularly when democracy is exogenously imposed. It is not sufficient to have democratic attitudes; these attitudes must be strongly supported by the deeper-rooted idea that fundamentalism produces very high social costs.

In particular the novel aspect of the model we have presented is the dynamic implications on a population's democratic attitudes induced by exogenous imposition of formal rules.

Exporting democracy seems to be the new dominant doctrine in international politics: democratic countries feel they have to induce democratic reforms in the undemocratic countries, even to the extent of using imposition. However a lot of papers underline both the relevance of diffused democratic attitudes among agents and a sufficient level of economic well-being as necessary prerequisites to assure the consolidation of democratic reforms (Zak and Fneg, 1998 and 2003; Barro, 1996). Empirical works give evidence of both a prevailing presence of undemocratic regimes in poor countries and of a disinclination of the poor to engage in public demonstrations against undemocratic politicians (see Barro, 1999); so it might be very difficult to export democracy to poor and undemocratic countries.

Thus, in terms of our model, we have justifiably correlated the relevance of democratic values to the level of economic and institutional development, in the sense that transformations of the economic environment changes the incentives to manifest democratic attitudes and claims for civil liberties. This hypothesis has interesting consequences on the dynamics of the population's democratic preferences:

1) exporting civil liberties when democratic values are not sufficiently supported, creates fragile democracies, in the sense that no significant change in people's attitudes and expectations occurs; so democracy can not sustain itself efficiently in the long run. In a situation like this a sustainable democracy can only flourish if economic and social development are at a sufficiently high level to support the increase of civil liberties: as in [3] the increase of wealth induces democrats to fight for their values (the relevance of democratic values increases) imposing virtuous dynamics in the population's preferences which will transform formal institutions and produce a consolidated democracy(Note 1);

2) Dictatorship shows the same fragility as democracy when the incentives to claim democracy increase. In extreme cases, even if the fundamentalist dictatorship imposes a 
tragic reduction of the relevance of democratic values, we observe a total absence of population's dynamics: all drastic attempts to destroy democratic attitudes will produce the effect of a behavioural inertia allowing them to survive and remerge when dictatorship ends. Paradoxically, the effects of fundamentalism on the dynamics of people's preferences is stronger if the manifestation of more democratic attitudes is not subject to tragic persecution by the regime.

\section{References}

Barro, R. (1996). Democracy and growth. Journal of Economic Growth, 1(1), 1-27. http://dx.doi.org/10.1007/BF00163340

Barro, R. (1999). Determinants of democracy. Journal of Political Economy, 107(6), 158-183. http://dx.doi:10.1086/250107

Bisin, A., \& Verdier, T. (2000). Public Policies and dynamics of cultural values in the welfare State. Mimeo, New York University and DELTA.

Bisin, A., \& Verdier, T. (2001). The economics of cultural transmission and the dynamics of preferences. Journal of Economic Theory, 97, 298-319. http://dx.doi.org/10.1006/jeth.2000.2678

Burkhart, R.E., \& Lewis-Beck, M.S. (1994). Comparative democracy: the economic development thesis. American Political Science Review, 88, 903-910. http://ir.uiowa.edu/cgi/viewcontent.cgi?article=1031\&context=polisci_pubs

Cavalli-Sforza, L., \& Feldman, M. (1981). Cultural transmission and evolution. Princeton University Press, Princeton.

Cavalli-Sforza, L. (1996). Geni, popoli e lingue. Adelphi Edizioni: Milano.

Cerqueti, R., Correani, L., \& Garofalo, G. (2013). Economic interactions and social tolerance:a dynamic perspective. Economics Letters, 120, 458-463. http://dx.doi.org/10.1016/j.econlet.2013.05.032

Corneo, G., \& Jeanne, O. (2009). A theory of tolerance. Journal of Public Economics, 93(5-6), 691-702. http://dx.doi.org/10.1016/j.jpubeco.2009.02.005

Dalton, J. R., \& Ong, N.T. (2003). Authority Orientations and Democracy Attitudes in East Asia: a test of the "Asian Values" hypothesis. Mimeo, Center for the study of democracy, University of California. http://www.socsci.uci.edu/ rdalton/archive/jjps05.pdf

Drezen, J., \& Sen, A. (1989). Hunger and public action. WIDER Studies in Development Economics. Oxford University Press, Oxford.

Inglehart, R., \& Welzel, C. (2003). Political Culture and democracy: analyzing Cross-Level linkages. Comparative Politics, 36(1), 61-79. http://dx.doi.org/10.2307/4150160

Iyer S. (2016). The New Economics of Religions. Journal of Economics Literature, 54(2), 
395-441. http://dx.doi.org/10.1257/jel.54.2.395

North, D.C. (1990). Institutions, institutional change and economic performance. Cambridge, Cambridge University Press.

Verba, S. (1965). Germany. In Lucian Pye, (ed.), Political Culture and Political Development. Princeton: Princeton University Press.

Zak, P.J., \& Feng, Y. (1998). Growth and the transition to democracy. Working paper, Claremont Graduate University.

Zak, P.J., \& Feng, Y. (1999). The determinants of democratic transitions. Journal of Conflict Resolution, 43(2), 162-177. http://dx.doi.org/ 10.1177/0022002799043002003

Zak, P.J., \& Feng, Y. (2003). A dynamic theory of the transition to democracy. Journal of $\begin{array}{lllll}\text { Economic Behavior and } & \text { Organization, }\end{array}$ http://dx.doi.org/10.1016/s0167-2681(03)00018-0

\section{Notes}

Note 1. An excellent survey on the relationship between religious traits and economics is in Iyer (2016).

Note 2. As Zak and Feng have argued, changes in income, wealth distribution and social setting alter the individual's perception of a political context; in particular, "civil liberties" become ever more attractive as wealth increases. In fact the literature seems to suggest that the educational effort of democratic agents, and intolerance towards autocratic regimes increases as economic development increases (see also Zak and Feng (1999) and Burkhart and Lewis (1994)).

Note 3. An individual's democratic orientation may not correspond to the attitude she manifests; the relationship between pro-democratic beliefs and effective behaviour strongly depends on the institutional context (similar considerations are in Dalton and Ong, 2003).

Note 4. A possible form of the utility function can be the weighted norm $U_{j}=-\|\bar{m}-\theta\|_{A_{j}}^{2}$ $j=1,2$ where $A_{j}$ is a diagonal matrix of salience terms $\operatorname{Diag}\left(A_{j}\right)=\left(a_{11}, a_{22}, a_{33}\right)$ with 1$)$ $a_{i i} \geq 0$ if $j=1$ and 2) $a_{11}=0, a_{22}=0$ and $a_{33} \geq 0$ if $j=2$. It can be easily shown that if $a_{11} \geq a_{22}$ then $V\left(t_{1}, t_{2}\right) \geq V\left(t_{2}, t_{1}\right)$.

Note 5. On the concepts of vertical and oblique transmission of cultural traits see Cavalli-Sforza and Feldman (1981) and Cavalli-Sforza (1996).

Note 6 . Note that $C(\tau)$ must be sufficiently convex so that the solution of the maximization 
problem is $\tau<1$.

Note 7. Identical considerations can be made if we start from a consolidated fundamentalist dictatorship $\widetilde{z}<z_{2,2}<\frac{1}{2}$ with $z_{1,2}>\frac{1}{2}$ such that if at time $t E\left(\theta^{f}\right)=t_{1}$ then $z_{t+1}\left(z_{t}\right)>\frac{1}{2}$.

Also in this case, if democratic agents expect a change of regime (from dictatorship to democracy), such a change occurs generating a virtuous convergence toward more democratic institutions.

Note 8 . The reduction of relevance can be justified by the very high costs an agent sustains if she shows attitudes other than dictatorial group's preferences.

Note 9. Relevance may be reduced by promising violent actions (segregation, tortures, arrest, deportations, sentence to death etc.) for example against all individuals manifesting preferences other than fundamentalism.

Note 10. This is the so called "prairie fire effects", by which a small change in economic fundamentals induces a large change in political instability (see Zak and Feng (2003) and Drezen and Sen (1989)).

\section{Appendix}

Proof of proposition 1: Consider the dynamic equation of population $z_{t+1}=z_{t}+z_{t}\left(1-z_{t}\right)\left(\tau_{t}^{1}-\tau_{t}^{2}\right)$; we note that it has three rest points: i) $z=0$, ii) $z=1$ and iii) $z=z^{*}$ with $\tau^{1}=\tau^{2}$.

Deriving the dynamic equation with respect to $z_{t}$ we obtain

$$
\frac{\partial z_{t+1}}{\partial z_{t}}=1+\left(1-2 z_{t}\right)\left(\tau^{1}-\tau^{2}\right)+z_{t}\left(1-z_{t}\right)\left(\frac{\partial \tau^{1}}{\partial z_{t}}-\frac{\partial \tau^{2}}{\partial z_{t}}\right)
$$

then

$\left.\frac{\partial z_{t+1}}{\partial z_{t}}\right|_{z_{t}=0}=1+\tau^{1}>1$, because $z_{t}=0$ implies $\tau^{2}=0$ and $\left.\frac{\partial z_{t+1}}{\partial z_{t}}\right|_{z_{t}=1}=1+\tau^{2}>1$ given that

when $z_{t}=1$ then $\tau^{1}=0$. Hence, then points $z=0$ and $z=1$ are not stable.

To evaluate the stability of point $z^{*}$, rewrite the derivative of dynamic equation as

$$
\frac{\partial z_{t+1}}{\partial z_{t}}=1+\left(1-2 z_{t}\right)\left(\tau^{1}-\tau^{2}\right)+z_{t}\left(1-z_{t}\right)\left(\frac{-\beta \Delta^{1}}{C^{\prime \prime}\left(\tau^{1}\right)}-\frac{\beta \Delta^{2}}{C^{\prime \prime}\left(\tau^{2}\right)}\right)
$$




\section{Macrothink}

where $\quad \Delta^{1}=\frac{C^{\prime}\left(\tau^{1}\right)}{\beta(1-z)}$ and $\Delta^{2}=\frac{C^{\prime}\left(\tau^{2}\right)}{\beta z}$. Substituting, we obtain

$$
\frac{\partial z_{t+1}}{\partial z_{t}}=1+\left(1-2 z_{t}\right)\left(\tau^{1}-\tau^{2}\right)+\left(z_{t} \frac{-C^{\prime}\left(\tau^{1}\right)}{C^{\prime \prime}\left(\tau^{1}\right)}-\left(1-z_{t}\right) \frac{C^{\prime}\left(\tau^{2}\right)}{C^{\prime \prime}\left(\tau^{2}\right)}\right)
$$

Evaluating this derivative in $z_{t}=z^{*}$, that is considering $\tau^{1}=\tau^{2} \equiv \tau$ and given $C^{\prime}<C^{\prime \prime}$ for each $\tau$ we have

$$
\left.\frac{\partial z_{t+1}}{\partial z_{t}}\right|_{z_{t}=z^{*}}=1-\frac{C^{\prime}(\tau)}{C^{\prime \prime}(\tau)} \in(0,1)
$$

and conclude that $z_{t}=z^{*}$ is locally stable.

Following the same arguments, we can show that with $\tau^{2}=0$ the unique stable steady state is $z=1$. In fact, the dynamic equation becomes

$$
z_{t+1}=z_{t}+z_{t}\left(1-z_{t}\right) \tau^{1}
$$

from which $\frac{\partial z_{t+1}}{\partial z_{t}}=1+\tau^{1}\left(1-2 z_{t}\right)$ and $\left.\frac{\partial z_{t+1}}{\partial z_{t}}\right|_{z=1}=1-\tau^{1} \in(0,1)$. Conversely, the other rest point $z=0$ is not stable because $\left.\frac{\partial z_{t+1}}{\partial z_{t}}\right|_{z=0}=1+\tau^{1}>1$

Proof of Lemma 1: Given the imperfect empathy hypothesis and preferences of the fundamentalist agent $U^{1,1}\left(\theta^{e}\right)>U^{1,2}\left(\theta^{e}\right)$ and $U^{2,2}(0)>U^{2,1}\left(\left|m_{1}-m_{2}\right|\right)$; consequently, by the first order condition of parent's maximization problem, each type of agent chooses a positive educational effort, $\tau^{1}>0$ and $\tau^{2}>0$.

To obtain the point $z^{*}\left(\theta^{e}\right)$ we have to consider that $\tau^{1}>\tau^{2}$ implies $C^{\prime}\left(\tau^{1}\right)>C^{\prime}\left(\tau^{2}\right)$. Then $\beta \Delta^{1}(1-z)>\beta \Delta^{2} z$ and thus $z<\frac{\Delta^{1}}{\Delta^{1}-\Delta^{2}}$, with $\Delta^{i}=U^{i, i}\left(\theta^{e}\right)-U^{i, j}\left(\theta^{e}\right) \quad i \neq j$

Proof of Lemma 2: Let us consider $U_{h, k}^{1, j}$ the utility a parent of type $t_{1}$ has from the action of her child of type $t_{j}$ when formal and informal institutions are respectively $\theta^{f}=t_{h}$ and $\theta^{n f}=t_{k}$. Moreover, let $z_{h, k}$ be the steady state when $\theta^{f}=t_{h}$ and $\theta^{n f}=t_{k}$. 
Then $z_{h, k} \geq z_{i, j}$ if

$$
\frac{U^{2,2}-U^{2,1}}{U_{h, k}^{1,1}-U_{h, k}^{1,2}+U^{2,2}-U^{2,1}} \leq \frac{U^{2,2}-U^{2,1}}{U_{i, j}^{1,1}-U_{i, j}^{1,2}+U^{2,2}-U^{2,1}} .
$$

The relationship is satisfied only if $U_{h, k}^{1,1}-U_{h, k}^{1,2} \geq U_{i, j}^{1,1}-U_{i, j}^{1,2}$. So $z_{1,1} \geq z_{1,2}$ if $U_{1,1}^{1,1}-U_{1,1}^{1,2} \geq U_{1,2}^{1,1}-U_{1,2}^{1,2}$ which holds given that $U_{h, k}^{1, j}$ is the maximum utility function and so that $U_{1,1}^{1,1} \geq U_{1,2}^{1,1}$ and $U_{1,1}^{1,2} \leq U_{1,2}^{1,2}$ where equality holds if $\theta^{\text {nf }}$ has null relevance. Following the same procedure we can show that $z_{1,1} \geq z_{2,1}, z_{1,1} \geq z_{2,2}, \quad z_{2,2} \leq z_{1,2}, \quad z_{2,2} \leq z_{2,1}$. The relation between $Z_{1,2}$ and $z_{2,1}$ depends on the relative importance of formal and informal institutions; thus $Z_{1,2}>z_{2,1}$ if $U_{1,2}^{1,1}-U_{1,2}^{1,2}>U_{2,1}^{1,1}-U_{2,1}^{1,2}$ which is verified only if formal institutions are more relevant to democrats, that is if $U_{1,2}^{1,1}>U_{2,1}^{1,1}$ and $U_{1,2}^{1,2}<U_{2,1}^{1,2}$.

Proof of Proposition 2: by imposing $U_{2,2}^{1,1}-U_{2,2}^{1,2}<U^{2,2}-U^{2,1}$ we have the starting point $z_{2,2}<\frac{1}{2}$; with the imposition $\theta^{f}=t_{1}$, by lemma $1 \tau^{1}>\tau^{2}$ and $z_{t}$ will tend to converge at $z_{1,2}: 1$ ) if $Z_{1,2}>\frac{1}{2}$ then $z_{t}$ will overtake $\frac{1}{2}$ and, by assumption on institutional dynamics, $\theta^{\text {nf }} \rightarrow t_{1}$; at this point the new attractor will be $\left.z_{1,1}>z_{1,2} ; 2\right)$ if $z_{1,2}<\frac{1}{2}$ then $z_{t}$ will monotonically converge to $Z_{1,2}$. When the imposition ends we again have $z<\frac{1}{2}$ and by assumption on institutional dynamics $\theta^{f} \rightarrow t_{2} ;$ at this point the new attractor will be $z_{2,2}$.

Proof of Proposition 3: by imposing $U_{1,1}^{1,1}-U_{1,1}^{1,2}>U^{2,2}-U^{2,1}$ we have the starting point $Z_{1,1}>\frac{1}{2}$; with the imposition $\theta^{f}=t_{2}$, by lemma $1 \tau^{1}<\tau^{2}$ and $z_{t}$ will tend to converge at $z_{2,1}: 1$ ) if $Z_{2,1}<\frac{1}{2}$ then $Z_{t}$ will get over $z=\frac{1}{2}$ and by assumption on institutional dynamics $\theta^{\text {nf }} \rightarrow t_{2}$; at this point the new attractor will be $\left.z_{2,2}<z_{2,1} ; 2\right)$ if $z_{2,1}>\frac{1}{2}$ then $z_{t}$ will monotonically converge to $z_{2,1}$; when imposition ends we again have $z>\frac{1}{2}$ and by assumption on institutional dynamics $\theta^{f} \rightarrow t_{1}$; at this point the new attractor will be $z_{1,1}$ 


\section{Copyright Disclaimer}

Copyright for this article is retained by the author(s), with first publication rights granted to the journal.

This is an open-access article distributed under the terms and conditions of the Creative Commons Attribution license (http://creativecommons.org/licenses/by/3.0/). 